\title{
A Review on Fuzzy-GA Based Controller for Power Flow Control in Grid Connected PV System
}

\author{
Raghu Thumu ${ }^{1}$, K. Harinadha Reddy ${ }^{2}$ \\ ${ }^{1}$ K L University \& Associate Professor, EEE Department, Anurag Engineering College, Kodad, India \\ ${ }^{2}$ Department of Electrical and Electronics Engineering, K L University, Andhra Pradesh, India
}

\begin{tabular}{l} 
Article Info \\
\hline Article history: \\
Received May 5, 2016 \\
Revised Sep 18, 2016 \\
Accepted Oct 1, 2016 \\
\hline Keyword: \\
Fuzzy logic controller (FLC) \\
Flexible AC transmission \\
system (FACTS) \\
Genetic algorithm (GA) \\
Photo voltaic (PV) system \\
Unified power flow controller \\
(UPFC)
\end{tabular}

\begin{abstract}
Now-a-days Renewable Energy Sources became an alternative to meet the increasing load demand because they are environmental friendly and also available abundant in nature. Among the Renewable Energy Sources, the Photo Voltaic (PV) System is gaining more attention due abundant availability of solar energy. The Maximum Power Point Tracking Technique is used to extract maximum power from the Photo Voltaic (PV) Array. When there is a need to transfer bulk amount of power from PV Array to Power Grid, the power quality issues, especially the real and reactive power flow problems, are a major concern. In this paper a novel control technique was proposed to control the power flow and to deal with power quality issues that arise when PV Array is integrated with power grid. It consists of a Fuzzy-GA based Cascaded Controller fed Flexible AC Transmission System device, namely Unified Power Flow Controller, for effective control of real and reactive power flow in grid connected photovoltaic system. The output of the Fuzzy Logic Controller is a control vector which is fine tuned by using Genetic Algorithm approach.
\end{abstract}

Copyright $\odot 2017$ Institute of Advanced Engineering and Science. All rights reserved.

\section{Corresponding Author:}

Raghu Thumu,

Research Scholar, Department of Electrical and Electronics Engineering,

K L University,

Greenfields, Vaddeswaram, Guntur (Dt), Andhra Pradesh, India.

Email: thumuraghu@gmail.com

\section{INTRODUCTION}

Photovoltaic (PV) energy has grown at an average annual rate of $60 \%$ in the last five years, surpassing one third of the cumulative wind energy installed capacity, and is quickly becoming an important part of the energy mix in some regions and power systems. This growth has also triggered the evolution of classic PV power converters from conventional single phase grid-tied inverters to more complex topologies to increase efficiency, power extraction from the modules, and reliability without impacting the cost. Solar PV energy conversion systems have had a huge growth from an accumulative total power equal to approximately $1.2 \mathrm{GW}$ in 1992 to $136 \mathrm{GW}$ in 2013 [1]. The factors which are responsible for this tremendous growth are cost reduction, increase in efficiency of the PV modules, the search for alternative clean energy sources, increased environmental awareness and favorable political regulations from local governments.

Grid-connected PV systems account for more than 99\% of the PV installed capacity compared to stand-alone systems. Storage batteries are not required in grid connected photovoltaic system since all of the power generated by the PV plant is uploaded to the grid for direct transmission, distribution, and consumption. The generated PV power reduces the use of other energy sources feeding the grid, such as hydro or fossil fuels, whose savings act as energy storage in the system, providing the same function of power regulation and backup as a battery would deliver in a stand-alone system. 
The power-electronic technology plays an important role in integration of renewable energy sources into the electrical grid. During the last few years, power electronics has undergone a fast evolution, which is mainly due to two factors. The first one is the development of fast semiconductor switches that are capable of switching quickly and handling high powers. The second factor is the introduction of real-time computer controllers that can implement advanced and complex control algorithms. A common feature of the renewable energy based or micro sources based Distributed Generation systems is the power electronics interfaces that required to convert the energy sources output to the grid ready voltages [2]. Due to increasing power demand throughout the world, Photovoltaic (PV) power supplied to the utility grid is gaining more and more visibility [3]. Not many PV systems have so far been placed into the grid due to the relatively high cost, compared with more traditional energy sources such as oil, gas, coal, nuclear, hydro, and wind. Solid-state inverters have been shown to be the enabling technology for putting PV systems into the grid [4].

Grid-connected PV systems are classified into two categories, one is distributed and the other is centralized. Grid-connected distributed PV systems are installed to provide power to a grid-connected customer or directly to the electric network. The advantages of these systems are low distribution losses in the electric network as the system is installed at the point of use, extra land is not required and costs for mounting the systems can be reduced if the system is mounted on an existing structure and the PV array itself can be used as a cladding or roofing material, as in building-integrated PV. Typical sizes are 1 to $4 \mathrm{~kW}$ for residential systems, and $10 \mathrm{~kW}$ to several MW for roof tops on public and industrial buildings.

Grid-connected centralized PV systems perform the functions of centralized power stations. The power supplied by such a system is not associated with a particular electricity customer, and the system is not located to specifically perform functions on the electricity network other than to supply bulk power. Typically, centralized systems are mounted on the ground, and they are larger than $1 \mathrm{MW}$. The economic advantages of these systems are the optimization of installation and operating costs by bulk buying and the cost effectiveness of the PV components and balance of systems on a large scale. In addition, there liability of centralized PV systems can be greater than distributed PV systems because they can have maintenance systems with monitoring equipment, which can be a smaller part of the total system cost [5].

\section{PV CELL MODEL}

Solar photovoltaic (PV) systems directly convert solar energy into electricity. PV Cell is the basic building block of PV system, which is a semiconductor device that converts solar energy into direct current electricity. PV cells are interconnected to form a PV module, typically 50 to $200 \mathrm{~W}$. The PV modules, combined with a set of additional application dependent system components (e.g., inverters, batteries, electrical components and mounting systems), form a PV system. PV systems are highly modular, i.e., modules can be linked together to provide power ranging from a few watts to tens of megawatts. The most established solar PV technologies are silicon based systems. More recently, so called thin film modules, which can also consist of non-silicon semiconductor material, have become increasingly important. Although thin films generally have a lower efficiency than silicon modules, their price per unit of capacity is lower.

Solar PV combines two advantages. On the one hand, module manufacturing can be done in large plants, which allows for economies of scale. On the other hand, PV is a very modular technology. Compared to concentrating solar power (CSP), where sunlight is focused onto a smaller area, PV has the advantage that it uses not only direct sunlight but also the diffuse component of sunlight, i.e., solar PV produces power even if the sky is not completely clear. This capability allows the effective deployment in many more regions in the world than for CSP [6].

The basic PV Cell model is shown in Figure 1.

$\mathrm{R}_{\mathrm{s}}$

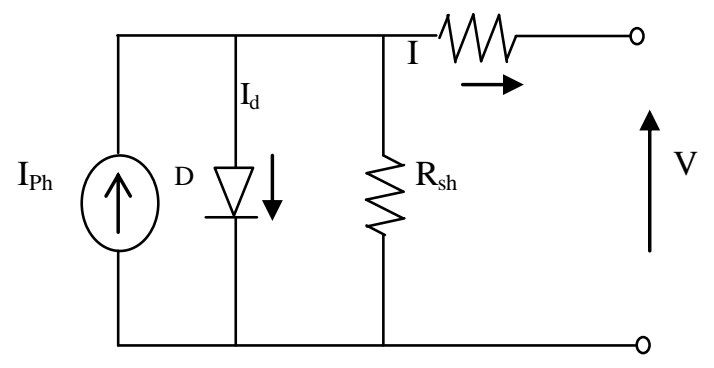

Figure 1. Basic PV Cell Model 
The current source is directly proportional to the light that focuses on the cell (photocurrent). The output current of the current source is in fact related to solar irradiation and temperature, according to:

$$
\mathrm{I}_{\mathrm{ph}}=\left[\mathrm{I}_{\mathrm{sc}}+\mathrm{K}_{1}(\mathrm{~T}-298)\right] \frac{\mathrm{G}}{100}
$$

Where $\mathrm{K}_{1}$ is the cells short-circuit current temperature coefficient, $I_{s c}$ the cells short-circuit current at $25{ }^{\circ} \mathrm{C}$, $T$ is the cell's temperature and $G$ is the solar irradiance in $\mathrm{W} / \mathrm{m}^{2}$. Considering $\mathrm{I}_{\mathrm{d}}$ the current flowing through the diode and I the output current, the I-V characteristic of the PV cell is defined by:

$$
I=I_{p h}-I_{d}-\frac{V+R_{s} I}{R_{s h}}
$$

Where $V$ is the output voltage of the solar cell, $R_{s}$ the series resistance and $R_{s h}$ the shunt resistance.

\section{GRID CONNECTED PV SYSTEM}

The grid connected photovoltaic (PV) system not only generates active power but also it acts as a reactive power compensator, especially at peak hours, when the main grid needs reactive power higher than average consumption. Due to the intermittent nature of solar power, voltage fluctuation is one potential issue associated with grid integration. The intermittency in power occurs mainly due to two phenomena known as 'ramping' (the rapid output variations that occur as clouds pass overhead) and 'cloud edge effect' (where the edge of a cloud acts like a lens, when the sun is behind it).

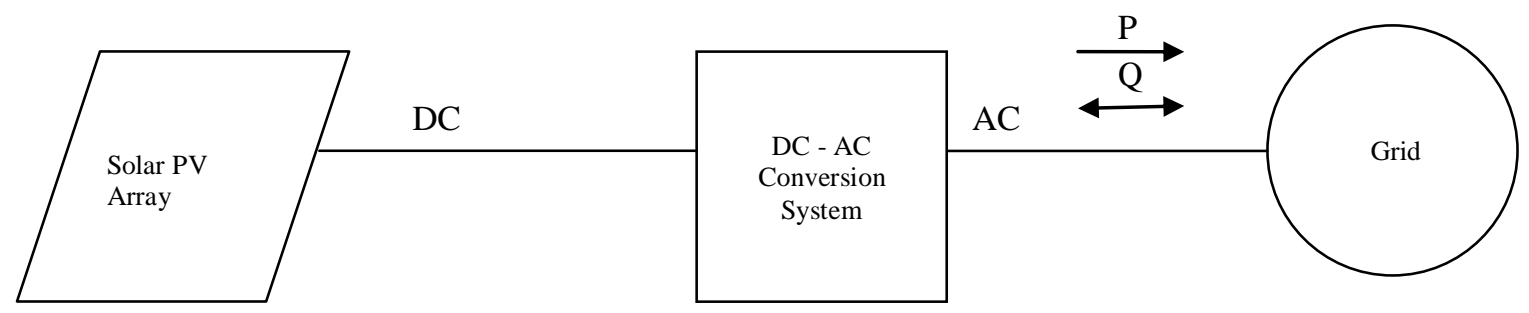

Figure 2. Grid Connected PV System

In a conventional PV system, the PV cells (arranged in a single module, a string of series-connected modules, or an array of parallel-connected strings) generate a dc current that greatly depends on the solar irradiance, temperature, and voltage at the terminals of the PV system. This dc power is transformed and interfaced to the grid via a PV inverter. Additional elements include a grid connection filter, a grid monitor or interaction unit (for synchronization, measurements, anti island detection, etc.), and a low-frequency transformer (which is optional depending on local regulations, the converter topology, and the modulation used to control it). Another option is an intermediate dc-dc power stage between the PV modules and the grid-tied inverter. This optional stage decouples the PV system operating point from the PV inverter grid control. Additionally, it can boost the PV system dc output voltage if required or provide galvanic isolation and perform maximum power point tracking (MPPT) control [7].

The increase in the PV installed capacity has also sparked a continuous evolution of the PV power conversion stage. Gradually, PV power converters have become extremely efficient, compact, and reliable, allowing the maximum power to be obtained from the sun in domestic, commercial, and industrial applications [8],[9]. The major elements of a grid-connected PV system that does not include storage are shown in Figure 2. The inverter may simply fix the voltage at which the array operates or use a maximum power point tracking function to identify the best operating voltage for the array. The inverter operates in phase with the grid (unity power factor), and is generally delivering as much power as it can to the electric power grid given the available sunlight and temperature conditions. The inverter acts as a current source; it produces a sinusoidal output current but does not act to regulate its terminal voltage in any way.

\section{CONTROL STRATEGIES FOR GRID CONNECTED POWER CONVERTERS}

Synchronous rotating reference frame, also denoted as $d q$ frame, the control is implemented in a reference frame which rotates with the same frequency as the grid angular frequency. In order to transform 
the feedback variables in this reference frame, the phase angle of grid voltage is necessary (Equation (4)), constituting a disadvantage of this structure. However, the control variables transformed in $d q$ frame appear as dc quantities, hence facilitating easier control and signal processing, e.g. filtering. In this situation, employment of PI controllers for current regulation is appropriate, however, as Figure 3 illustrates, crosscoupling terms and grid voltage feed-forward may be necessary in order to obtain best results

$$
\begin{aligned}
& V_{d q}=\left[\begin{array}{ll}
V_{d} & V_{q}
\end{array}\right]^{T}=\left[\begin{array}{ll}
T_{d q}
\end{array}\right] U_{\alpha \beta} \\
& V_{d q}=\left[\begin{array}{cc}
\cos \theta & \sin \theta \\
-\sin \theta & \cos \theta
\end{array}\right] V_{\alpha \beta}
\end{aligned}
$$

PWM driven voltage source inverters are largely utilized in drives applications especially where adjustable speed is necessary [10]-[11].

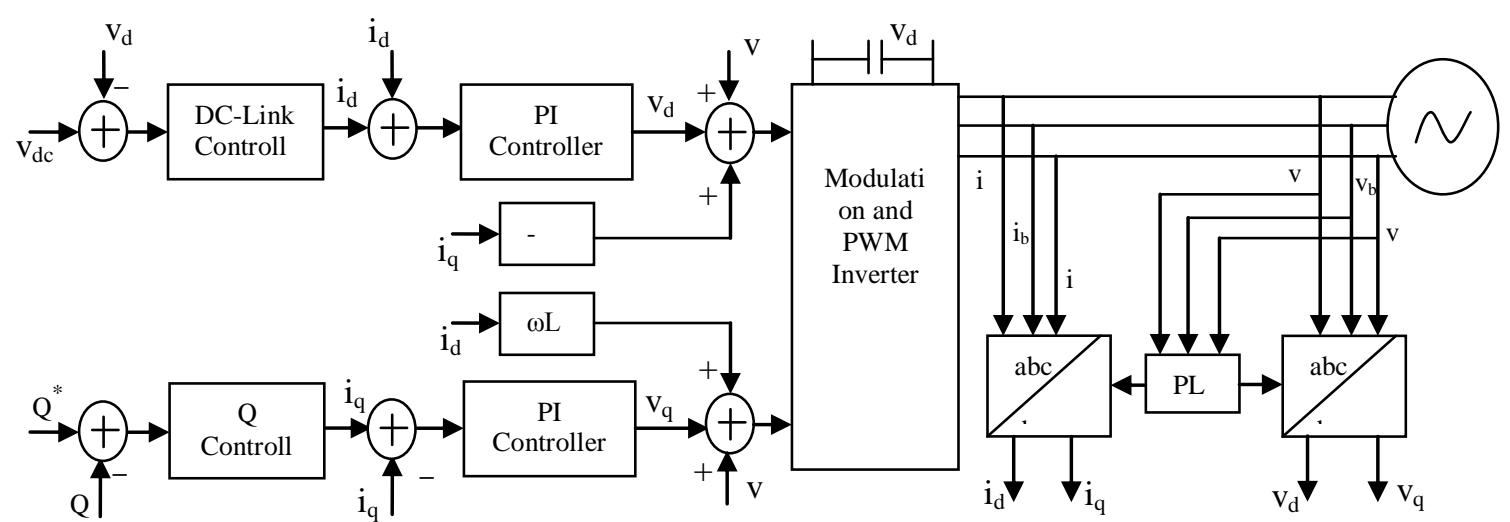

Figure 3. Structure of control implemented in synchronous rotating reference frame using PI controllers for current regulation

Normally, multiple cascaded loops are used to control PWM driven VSI converters. As illustrated in Figure 3, the most common strategy is the dc-link voltage control cascaded with an inner current loop control [12-18]. When implemented in a reference frame other than $a b c$, control can be oriented to the grid voltage vector or the virtual flux vector [19-20]. In the situation when reactive power control is demanded at the point of common coupling, a reactive power controller can be used whereas, in case unity power factor is a must, the reactive current reference $\mathrm{i}_{\mathrm{q}}{ }^{*}$ can be set to zero, hence no reactive power controller is necessary. A third level loop controlling the grid frequency and the grid voltage amplitude can also be implemented in case of Distributed Power Generation System, providing frequency and voltage control at the point of common coupling.

Moreover, in the above strategies, the dc-link voltage control can be replaced by an active power control [21-23] supposing that an active and reactive power reference is supplied to the grid side converter. In addition, direct power control [24-25] is another possible control technique which can be applied to PWM driven power converters.

\section{GENETIC ALGORITHM}

Now a day's, researchers have become increasingly showing interested in the use of Genetic Algorithms to control various types of systems. These Algorithms are robust search techniques based on the evolution principals. Extensive wide area research has been performed exploiting the robust properties of Genetic Algorithms and showing their Capabilities across a broad range of problems. These evolutionary methods have gained identification as general problem solving techniques in many applications, like functional optimization, classification and machine learning, image processing, training of neural networks.

Genetic algorithm is popular optimization technique that maps input characteristics to output characteristics with fulfilling of user require constraints. Proposed genetic algorithm in step by step procedure is represented as follows:

Step1 : Individual solutions are randomly generated to form an Initial population. 
Step2 : The degree of conformity of each object is calculated and an individual is reproduced under a fixed Rule depending on the degree of conformity.

Step3 : Two parents from the existing population to perform Crossover.

Step4 : Choose random mutation 'or' alternate bit mutation Control the mutation.

Step5 : Termination with condition

$\mathrm{t}=0$

The following code gives the basic algorithmic steps for GA [26].

initialize $\mathrm{P}(\mathrm{t})$

evaluate structures in $\mathrm{P}(\mathrm{t})$

repeat

$\mathrm{t}=\mathrm{t}+1$

select- reproduction $\mathrm{C}(\mathrm{t})$ from: $\mathrm{P}(\mathrm{t}-1)$

combine and mutate structures in $\mathrm{C}(\mathrm{t})$ forming $\mathrm{C}^{\prime}(\mathrm{t})$;

evaluate structures in $\mathrm{C}^{\prime}(\mathrm{t})$

select-replace $\mathrm{P}(\mathrm{t})$ from $\mathrm{C}^{\prime}(\mathrm{t})$ and $\mathrm{P}(\mathrm{t}+1)$;

Until (termination condition satisfied)

After the initial population of individuals is generated (usually randomly) and individual's structures are evaluated, the loop is entered. Then a selection buffer $\mathrm{C}(\mathrm{t})$ is created to accommodate the selected copies from $\mathrm{P}(\mathrm{t}-\mathrm{l})$, "select-reproduction". In the Holland original GA, individuals are selected probabilistically by assigning each individual a probability proportional to its structural fitness. Thus, better individuals are given more opportunity to produce offspring. Next the variation operators (mutation and crossover) are applied to the individuals in $\mathrm{C}(\mathrm{t})$ buffer producing offspring $\mathrm{C}(\mathrm{t})$. After evaluating the structural fitness of $\mathrm{C}(\mathrm{t})$, the selection method is applied to select replacement for $\mathrm{P}(\mathrm{t})$ from $\mathrm{C}^{\prime}(\mathrm{t})$ and $\mathrm{P}(\mathrm{t}-1)$.

\section{FUZZY LOGIC CONTROLLER}

The main elements of the Fuzzy Logic Controller are the fuzzifier at the input terminal, rule base or knowledge base, inference engine and defuzzifier at the output terminal as shown in Figure 4. The input variables and output variables are the required variables in the Fuzzy Logic Control System. The inputs to the Fuzzy Logic Controller are the parameters or variables of the process to be controlled.

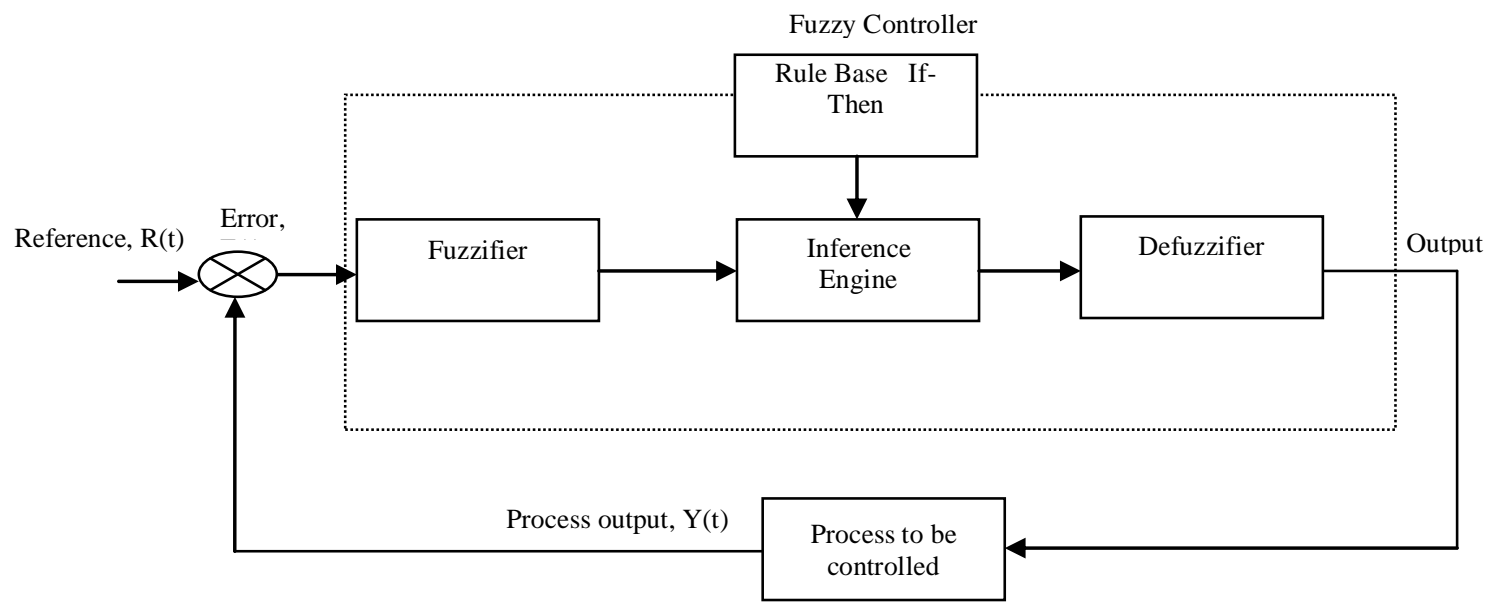

Figure 4. Basic Fuzzy Logic Controller

Error and the rate of change of error are chosen as input variables, change of current and change of voltage are chosen as output variables. Error, $\mathrm{E}(\mathrm{t})$ is defined as the difference between the desired output or reference, $R(t)$ and the process output variable, $\mathrm{Y}(\mathrm{t})$.

$$
\begin{aligned}
& \mathrm{E}(\mathrm{t})=\mathrm{R}(\mathrm{t})-\mathrm{Y}(\mathrm{t}) \\
& \Delta \mathrm{E}(\mathrm{t})=\mathrm{E}(\mathrm{t})-\mathrm{E}(\mathrm{t}-1)
\end{aligned}
$$


The current error, $\mathrm{E}(\mathrm{t})$ and the change of error $\Delta \mathrm{E}(\mathrm{t})$ are defined in equations (5) and (6), respectively. The input variables are fuzzified through the membership functions. The controller reduces the error signal in a faster manner and increases the system transient response by using triangular and trapezoidal membership functions. Rule-based or knowledge-based element, which consists of a list of fuzzy rules, is the important part of the Fuzzy Logic Controller. According to If-Then rules the inference process will generate a fuzzy output set. With these rules, the fuzzy controller behaves intelligently and capable of imitating humanlike-decision.

Linguistic terms used for the membership functions are such that, the terms will be NL(Negative Large), NM(Negative Medium), NS(Negative Small), ZE(Zero), PS(Positive Small), PM(Positive Medium) and PL(Positive Large). Membership Grade NL NM NS ZE. Rules are formed with 49 rule base [27] and expressed in linguistic variables relating input signals to the control signal and shown in Table 1.

Table 1. Knowledge base Table with 49 Rules

\begin{tabular}{cccccccc}
\hline$E$ & & & \multicolumn{5}{c}{$\Delta e$} \\
& NL & NM & NS & ZE & PS & PM & PL \\
\hline NL & ZE & PS & PM & PL & PL & PL & PL \\
NM & NS & ZE & PS & PM & PM & PL & PL \\
NS & NM & NS & ZE & PS & PS & PM & PL \\
ZE & NM & NM & NS & ZE & PS & PM & PM \\
PS & NL & NM & NS & NS & ZE & PS & PM \\
PM & NL & NL & NM & NM & NS & ZE & PS \\
PL & NL & NL & NL & NL & NM & NS & ZE \\
\hline
\end{tabular}

\section{CASCADED FUZZY LOGIC CONTROLLER}

Power conversion system is common is common engineering practice in our electrical power system. Example: Rectifiers, Inverters, FACTS Devices etc. Suitable controller is required for efficient operation of these Power conversion devices in their applications. Out of the wide variety of controllers as mentioned in the literature by so many authors, cascaded PI Controller is one among them which is suitable for all power conversion devices. Designing parameters for cascaded PI Controller is cumbersome due its non-linear properties, especially when application is in the area of electric power system. Here a new topology as shown in Figure 5 is proposed for optimum design procedure of the cascaded fuzzy controller used in power conversion system.

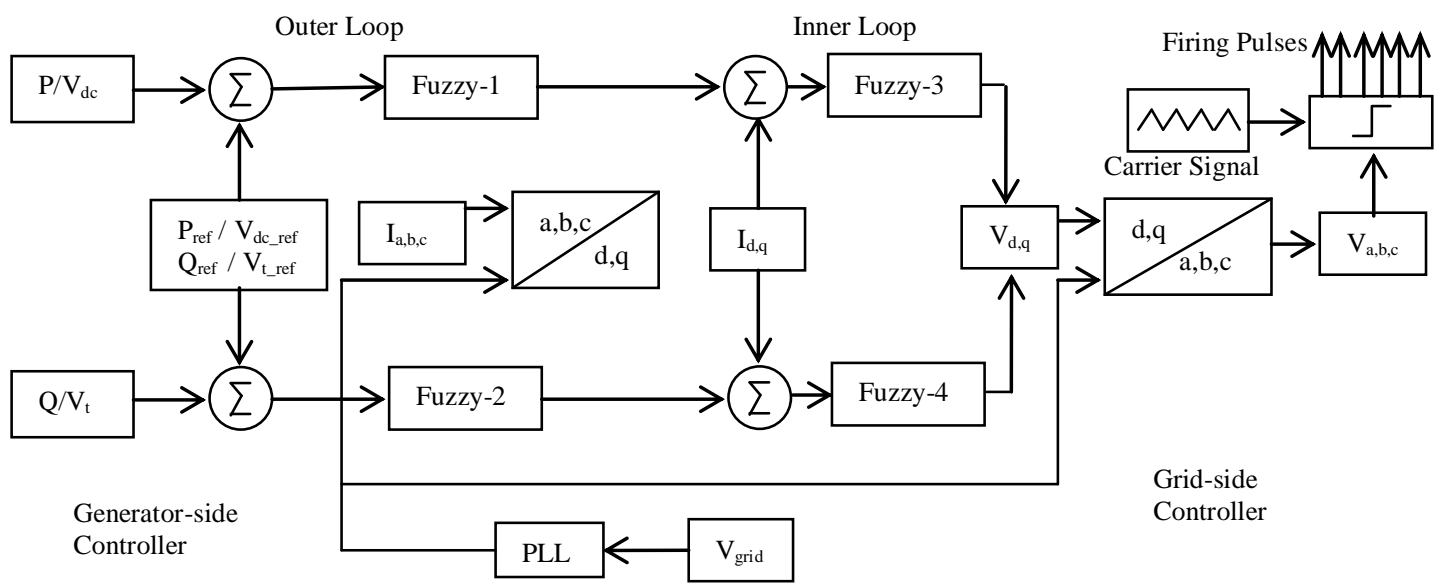

Figure 5. Cascaded Fuzzy-Logic Controller

In Figure 5 the quantities $\mathrm{P}, \mathrm{Q}, \mathrm{V}_{\text {grid }}, \mathrm{I}_{\mathrm{abc}}$ represents the measured or actual values. The transformation angle ' $\theta$ ', which is the output of phase locked loop (PLL), $I_{d q}, V_{d q}, V_{a b c}$ represents calculated values. The $\mathrm{P}_{\text {ref, }} \mathrm{Q}_{\text {ref }}$ represents reference values or set points. The cascaded fuzzy-logic controller consists of two loops, namely inner loop and outer loop, each loop contains two fuzzy controllers which progress the error signals. The final outputs from the cascaded controller are the three-phase voltage references which 
generate the pulse width modulation (PWM) signal to drive the power electronic switches of the power converter. The output of the fuzzy controller is a controlled vector applied to the power electronic switches. Tuning of four fuzzy controllers is a cumbersome process and time consuming. Therefore, this study attempts to find a way to optimally design the cascaded controller parameters used in the power conversion system.

\section{PROPOSED SYSTEM}

The cascaded fuzzy-logic controller consists of two loops, namely inner loop and outer loop, each loop contains two fuzzy controllers which progress the error signals. The final outputs from the cascaded controller are the three-phase voltage references which generate the pulse width modulation (PWM) signals to drive the power electronic switches of the power converter. The output of the fuzzy logic controller is a controlled vector which is fine tuned by Genetic Algorithm and is applied to the power electronic switches for better controllability.

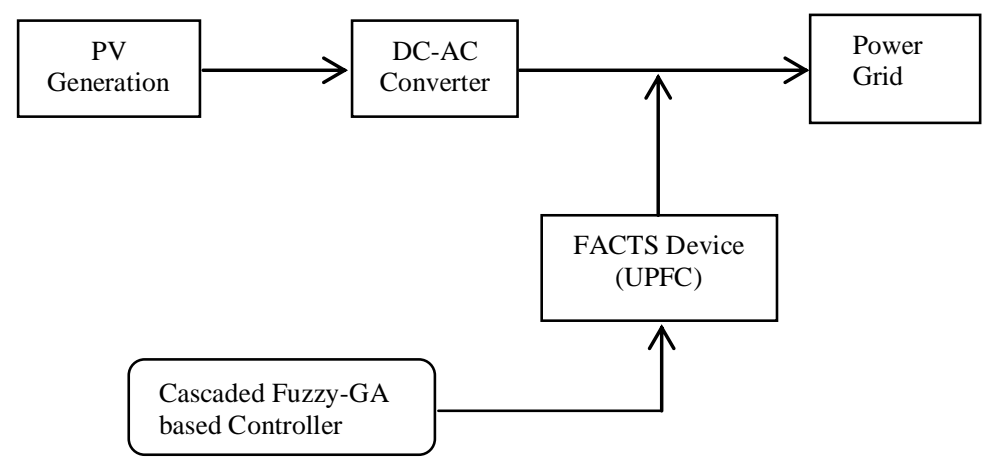

Figure 6. Grid Connected PV system with Proposed Controller and FACTS device

Figure 6 shows a photovoltaic system connected to the utility grid through a single stage conversion by using inverter i.e., DC/AC Conversion. A FACTS Device, namely Unified Power Flow Controller (UPFC), is connected in between inverter and utility grid to regulate and control the power flow from Photo Voltaic (PV) system to the utility grid. The Unified Power Flow Controller (UPFC) consists of two voltagesource converters with turn-off capability, sharing a common dc link capacitor and connected to a power transmission system through coupling transformers.

The reactive power is generated/absorbed independently by each converter and does not flow through the dc link. The dc link provides a path to exchange active power between the converters. The injected voltage and line current determine the active and reactive power injected by the series converter. The series converter and shunt converter exchange reactive power with the ac system independently. The UPFC can provide simultaneous control of all basic power system parameters such as transmission voltage, impedance and phase angle. The controller can perform functions such as reactive shunt compensation, series compensation, and phase shifting, meeting multiple control objectives. The Proposed Cascaded Fuzzy-GA based Controller is connected to the UPFC for better controllability and to minimize the effect due to problems occurring on the grid side and generation side.

\section{CONCLUSION}

The proposed structure introduced in this paper improves functionality in grid connected photovoltaic generation systems. Various types of controllers have been proposed in the literature in order to extract maximum power from the photovoltaic Array and to increase the power transfer efficiency of the photovoltaic system. Out of these, cascaded control structure has proven to give better performance as compared to conventional control structures. But designing parameters for cascaded control structure is cumbersome due its non-linear properties, especially when application is in the area of electric power system. Hence a new topology is proposed for optimum design procedure of the cascaded fuzzy controller used in power conversion system. The output of the proposed controller is a controlled Vector, which is fine tuned by genetic algorithm technique. The proposed cascaded control scheme is applicable in the areas of renewable energy, energy storage systems, variable-speed drives, and FACTS devices used in the power systems, and many more. 


\section{REFERENCES}

[1] International Energy Agency, "PVPS report snapshot of global PV 1992-2013,” Rep. IEAPVPS T1-24: 2014.

[2] Carrasco J. M., et al., "Power-electronic systems for the grid integration of renewable energy sources: a survey," IEEE Trans Industrial Electronics, vol/issue: 53(4), pp. 1002-1016, 2006.

[3] Benner J. P. and Kazmerski L., "Photovoltaics gaining greater visibility," IEEE Spectrum, vol/issue: 36(9), pp. 3442, 1999.

[4] S. B. Kjaer, et al., "A Review of Single-Phase Grid-Connected Inverters for Photovoltaic Modules," IEEE Trans Industry Applications, vol/issue: 41(5), pp. 1292-1306, 2005.

[5] Sheikh N. and K. Dundar F., "A comprehensive assessment of solar photo- voltaic technologies: literature review," in Proceedings of the technology management in the energy smart world, PICMET, 2011.

[6] Marks N. D., et al., "Photovoltaic power systems: are view of topologies, converters and controls," in $22^{\text {nd }}$ Australian universities power engineering conference (AUPEC), 26-29, Sept 2012, pp. 1-6, 2012.

[7] S. Kumari J. and Saibabu Ch., "Maximum Power Point Tracking Algorithms for Grid-Connected Photovoltaic Energy Conversion System," International Journal of Power Electronics and Drive System (IJPEDS), vol/issue: 3(4), pp. 424-437, 2014.

[8] Teodorescu R., et al., "Grid Converters for Photovoltaic and Wind Power Systems," Piscataway, NJ, IEEE Press/Wiley, 2011.

[9] Carrasco J. M., et al., "Power-electronic systems for the grid integration of renewable energy sources: A survey," IEEE Trans. Ind. Electronics, vol/issue: 53(4), pp. 1002-1016, 2006.

[10] Abella M. and Chenlo F., "Choosing the right inverter for grid connected PV systems," Renewable Energy World, vol/issue: 7(2), pp. 132-147, 2004.

[11] Klumpner C., et al., "Alternate ASDs: evaluation of the converter topologies suited for integrated motor drives," IEEE Industry Applications Magazine, vol/issue: 12(2), pp. 71-83, 2006.

[12] Kazmierkowski M., et al., "Control in Power Electronics-Selected Problems," Academic Press, 2002.

[13] Blasko V. and Kaura V., "A novel control to actively damp resonance in input LC filter of a three-phase voltage source converter," IEEE Trans. on Industry Applications, vol/issue: 33(2), pp. 542-550, 1997.

[14] Agirman I. and Blasko V., "A novel control method of a VSC without AC line voltage sensors," IEEE Trans. on Industry Applications, vol/issue: 39(2), pp. 519-524, 2003.

[15] Song S. H., et al., "Implementation and control of grid connected AC-DC-AC power converter for variable speed wind energy conversion system," in Proc. of APEC '03, vol. 1, pp. 154-158, 2003.

[16] Teodorescu R., et al., "Flexible development and test system for $11 \mathrm{~kW}$ wind turbine," in Proc. of PESC'03, vol. 1, pp. 67-72, 2003.

[17] Zeng Q., et al., "SVPWM-based current controller with grid harmonic compensation for three-phase grid-connected VSI," in Proc. of PESC04, vol. 4, pp. 3494-3500, 2004.

[18] Teodorescu R. and Blaabjerg F., "Flexible control of small wind turbines with grid failure detection operating in stand-alone and grid-connected mode," IEEE Trans. on Power Electronics, vol/issue: 19(5), pp. 1323-1332, 2004.

[19] Malinowski M., et al., "Virtual-flux-based direct power control of three-phase PWM rectifiers," IEEE Trans. on Industry Applications, vol/issue: 37(4), pp. 1019-1027, 2001.

[20] Malinowski M., et al., "A comparative study of control techniques for PWM rectifiers in AC adjustable speed drives," IEEE Trans. on Power Electronics, vol/issue: 18(6), pp. 1390-1396, 2003.

[21] Prodanovic M. and Green T. C., "Control of power quality in inverter based distributed generation," in Proc. of IECON'02, vol. 2, pp. 1185-1189, 2002.

[22] Prodanovic M. and Green T., "Control and filter design of three-phase inverters for high power quality grid connection," IEEE Trans. on Power Electronics, vol/issue: 18(1), pp. 373-380, 2003.

[23] Candusso D., et al., "Modelling, control and simulation of a fuel cell based power supply system with energy management," in Proc. of IECON'02, vol. 2, pp. 1294-1299, 2002.

[24] Malinowski M., et al., "Simple direct power control of three phase PWM rectifier using space-vector modulation (DPC-SVM)," IEEE Trans. on Industrial Electronics, vol/issue: 51(2), pp. 447-454, 2004.

[25] Xu L. and Cartwright P., "Direct active and reactive power control of dfig for wind energy generation," IEEE Trans. on Energy Conversion, vol/issue: 21(3), pp. 750-758, 2006.

[26] X. Yan, et al., "An Improved Genetic Algorithm and Its Application," TELKOMNIKA Indonesian Journal of Electrical Engineering, vol/issue: 10(5), pp. 1081-1086, 2012.

[27] H. Reddy, "Power Control using Fuzzy Logic Controller in DFIG Wind Farm," IJST, vol/issue: 2(11), pp. 47-51, 2014. 


\section{BIOGRAPHIES OF AUTHORS}
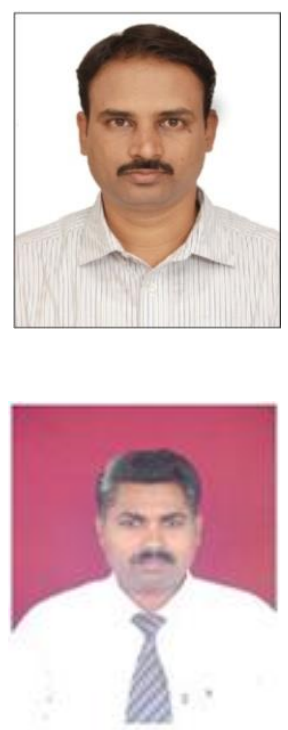

Mr.T.Raghu was born in Andhra Pradesh, India in the year 1979. He was Awarded B.Tech degree in Electrical and Electronics Engineering in the year 2002 from JNTU, Hyderabad. He completed M.Tech degree in Power Electronics in the year 2011 from JNTUH, Hyderabad. At Present he is Pursuing Ph. D degree at K L University, Andhra Pradesh, India. Also, he is working as Associate Professor in the Department of Electrical and Electronics Engineering at Anurag Engineering College, Kodad, India. His Research interest includes Renewable Energy Sources, Grid Connected PV System, FACTS Devices and Power Electronic Applications in Power System.

Dr.K.Harinadha Reddy was born in India on July 02, 1974. He received B.E. degree in Electrical and Electronics Engineering from K.U. in 1997, India. He completed M.Tech degree in Electrical Power Systems Emphasis High Voltage Engineering from J. N. T. UniversityKakinada Campus in 2006, India. He obtained Ph. D degree in Electrical Power Systems from Andhra University Campus in the year 2012. At present he is working as Professor in Electrical and Electronics Engineering department at K L University, India. 9 papers are published in various national and international journals. His research interests include AI techniques and their applications to Power System Operation, FACT devices and Integrated Energy Systems. 